Anales de Geografía de la Universidad Complutense ISSN: 0211-9803

http://dx.doi.org/10.5209/AGUC.60470

\title{
Identifiación, clasificación y análisis de las formas urbanas en ciudades medias: aplicación a las capitales provinciales de Castilla-La Mancha ${ }^{1}$
}

\author{
Pablo Prieto Medina ${ }^{2}$; Vicente Romero de Ávila Serrano ${ }^{3}$; Amparo Moyano Enríquez de \\ Salamanca $^{4}$; Eloy Solís Trapero ${ }^{5}$; José María Coronado Tordesillas ${ }^{6}$
}

Recibido: 29 de diciembre del 2016 / Enviado a evaluar: 1 de junio del 2017 / Aceptado: 14 de diciembre del 2017

Resumen. La identificación y análisis de las formas urbanas adquiere relevancia por dos motivos: (a) permite conocer cómo se ha desarrollado, cómo funciona y qué problemas tiene la ciudad en su conjunto y sus diferentes partes; (b) informa y guía procesos de intervención en el diseño y proyecto urbano. Los estudios existentes sobre forma urbana se han centrado tradicionalmente en las grandes ciudades, ignorando las formas y las lógicas de crecimiento de las pequeñas ciudades y de los municipios rurales. Este artículo, en base a un reciente sistema de análisis paramétrico de la forma física construida Spacemate, presenta un método de carácter objetivo, sistemático y extrapolable para la identificación, clasificación y análisis de formas urbanas válido para ciudades y asentamientos de diferente tamaño, dimensión, ubicación o bagaje histórico. La información relativa a la forma física que utiliza Spacemate ha sido recogida de Catastro y reelaborada y tratada con el apoyo de los Sistemas de Información Geográfica. Los resultados permiten establecer una catalogación de formas urbanas e identificación de problemas básicos que son un importante punto de partida para estrategias de intervención en la ciudad.

Palabras clave: Formas urbanas; ciudades medias; metodología Spacemate; parámetros urbanísticos; Castilla-La Mancha.

\footnotetext{
Este artículo se desarrolla en el marco del Plan Nacional de Investigación, Ref. CSO2015-63815-R, de la Secretaría de Estado de $\mathrm{I}+\mathrm{D}+\mathrm{i}$ del Ministerio de Economía y Competitividad.

2 ETSI Caminos, Canales y Puertos. Universidad de Castilla-La Mancha.

E-mail: pabloprimed@gmail.com

3 ETSI Caminos, Canales y Puertos. Universidad de Castilla-La Mancha.

E-mail: Vicente.romeroavila@uclm.es

4 ETSI Caminos, Canales y Puertos. Universidad de Castilla-La Mancha.

E-mail: amparo.moyano@uclm.es

5 Escuela de Arquitectura de Toledo. Universidad de Castilla-La Mancha

E-mail: eloy.solis@uclm.es

6 ETSI Caminos, Canales y Puertos. Universidad de Castilla-La Mancha.

E-mail: josemaria.coronado@uclm.es
} 


\title{
[en] Identification, classification, and analysis of urban forms in medium-sized cities: application to the provincial capitals of Castilla-La Mancha
}

\begin{abstract}
The identification and analysis of urban forms becomes relevant for two reasons: (a) it allows us to know how the city has developed, how it works, and what its problems are; (b) it inform and guide intervention processes in the design and urban project. Existing urban form classifications focus on big cities, ignoring the forms and growth logics of small towns and rural municipalities. This paper, based on a recent parametric analysis Spacemate of the physical form, presents an objective and systematic method for the identification, classification and analysis of urban forms that is able to be extrapolated to any population, regardless of its location, size or historical baggage. The information regarding the physical form used by Spacemate has been collected from the Cadastre and processes with the support of Geographic Information Systems. The results allow establishing a catalog of urban forms and identifying basic problems that are an important starting point for intervention strategies in the city.
\end{abstract}

Keywords: Urban forms; medium-sized cities; Spacemate methodology; urban parameters; Castilla-La Mancha.

\section{[fr] Identification, classification et analyse des formes urbaines dans villes moyennes: application aux capitales provinciales de Castilla-La Mancha}

Résumé. L'identification et l'analyse des formes urbaines devient importante pour deux raisons: (a) il nous permet de savoir comment la ville s'est développée, comment elle fonctionne et quels sont ses problèmes; (b) il informe et guide des processus d'intervention dans le design et le projet urbain. Les études existantes de la forme urbaine mettent l'accent sur les grandes villes, en ignorant les formes et les logiques de croissance des petites villes et des municipalités rurales. Cet article, basé sur une récente système d'analyse paramétrique de la forme physique construite Spacemate, présente une méthode d'identification, de classification et d'analyse valable pour les petites et moyennes villes, objectif et extrapolable à toutes les populations, indépendamment de leur emplacement, taille ou bagage historique. Les informations concernant la forme physique utilisées par Spacemate sont obtenues du Cadastre et traité avec le soutien des Systèmes d'Information Géographique. Les résultats permettent de cataloguer les formes urbaines et d'identifier des problèmes basiques, qui sont un point de départ important pour les stratégies d'intervention dans la ville.

Mots clés: Formes urbaines; villes moyennes; méthodologie Spacemate; paramètres urbains; Castilla La Mancha.

Cómo citar. Prieto Medina, P., Romero de Ávila Serrano, V., Moyano Enríquez de Salamanca, A., Solís Trapero, E. y Coronado Tordesillas, J.M. (2018): Identificación, clasificación y análisis de las formas urbanas en ciudades medias: aplicación a las capitales provinciales de Castilla-La Mancha. Anales de Geografia de la Universidad Complutense, 38(1), 87-112.

Sumario. 1. Introducción. 2. El estudio de la forma física urbana y sus implicaciones urbanísticas y socioeconómicas. 2.1. El origen del estudio de la forma urbana y el legado de Cervallati y Scannavini (1969). 2.2. "Formas urbanas: de la manzana al bloque", de Philippe Panerai (1986). 2.3. "Las formas de crecimiento urbano", de Manuel de Solà-Morales (1997). 3. Metodología. 4. Resultados. 5. Discusión y conclusiones. 5. Referencias bibliográficas. 


\section{Introducción}

En las últimas décadas, las ciudades medias y pequeñas españolas, así como los asentamientos de menor tamaño, han sufrido importantes transformaciones económicas, sociales, culturales, políticas y urbanas-territoriales. Estas transformaciones han actuado de forma ambivalente, en unos casos situando algunos de estos asentamientos en una posición de dinamismo y crecimiento, y en otros perpetuando o propiciando situaciones de estancamiento o retroceso (Ganau y Vilagrasa, 2003; ESPON, 2006; Capel, 2009; Méndez y Sánchez, 2010; Bellet et al., 2015).

Como resultado de las nuevas lógicas de producción-vivienda-consumocirculación capitalistas, las ciudades medias y pequeñas han asistido a un proceso de reestructuración urbana con una impronta espacial de gran calado (Más, 1996; Zárate, 1998; Troitiño, 2001; Mallarach y Vilagrasa 2002; Ganau y Vilagrasa, 2003; EEA, 2006; Burriel, 2008; Cebrián y Panadero, 2013; Capel, 2016). Sobre el tradicional modelo de ciudad compacta, densa y diversa, aunque no exento de ciertas carencias urbanísticas y conflictos sociales, ha emergido un nuevo modelo de ciudad que, de acuerdo a la suma de viejas y nuevas funciones y de las estrategias de agentes públicos y privados en un contexto neoliberal, tiende a modificar y reconfigurar el tejido urbano pre-existente, y a su vez a incrementar la ocupación de suelo. En este contexto existe un emergente debate sobre las consecuencias sociales, económicas y morfológicas de las ciudades en la etapa actual.

Reconociendo la interrelación o el proceso de ajuste permanente entre espaciosociedad o entre realidad física y realidad socioeconómica (Troitiño, 1983), en este artículo se sostiene la importancia de entender y explicar la forma urbana desde la dimensión física/espacial. La forma física urbana se presenta como un aspecto intrínseco de la sociedad, lo que significa que, por un lado, tiene el valor de ser un factor condicionante de los comportamientos socioeconómicos (Hillier y Vaughan, 2007), y por otro lado, nos ayuda a entender, caracterizar y comparar diferentes configuraciones espaciales que hoy constituyen la ciudad (Berghauser y Haupt, 2005; 2009). Podemos afirmar que el estudio de los rasgos físicos como una variable independiente supone una aproximación para interpretar, en parte, las dinámicas socioeconómicas y guiar estrategias conducentes a resolver problemas socioespaciales y relativos al diseño y al proyecto urbano (Solís et al., 2017).

La forma o morfología urbana refiere al estudio físico de lo construido, de los agentes y procesos que le dan forma, así como de sus interdependencias. La forma urbana de las ciudades es el resultado de la combinación de los diferentes elementos que las conforman (edificios, parcelas, manzanas, calles, espacios abiertos y zonas verdes) en función de unas lógicas urbanas, teóricas o estéticas variables a lo largo del tiempo (Panerai et al., 1986). Las formas urbanas permiten conocer cómo se ha desarrollado, cómo funciona y qué problemas puede tener el conjunto de la ciudad, así como cada uno de los elementos que conforma el tejido urbano. Por ello, el conocimiento de las mismas permite a los planificadores urbanos prever o identificar rápidamente las carencias, necesidades o dificultades de cada tipo de forma urbana y 
actuar en consecuencia, reduciendo el coste y el tiempo de sus actuaciones. Además, los estudios existentes sobre forma urbana se han centrado tradicionalmente en las grandes ciudades, ignorando las formas y las lógicas de crecimiento de las pequeñas ciudades y de los municipios rurales.

Para encuadrar el estudio de la forma física urbana y su influencia en la realidad socioeconómica y en la práctica del urbanismo, la justificación del método usado y las variables para medir la forma física y orientar el análisis se propone una aproximación a dos niveles. El primer nivel, supone una revisión internacional y nacional sobre la cuestión de la forma (física) urbana. En el segundo nivel se aplica un método, el Spacemate, automatizado, objetivo y basado en parámetros y resultados numéricos, extrapolables y comparables. El método consta de dos partes, una de identificación de las formas urbanas, donde se emplean la estadística, los SIG y las matemáticas, y otra de análisis de las formas urbanas, donde se emplea el Spacemate. El artículo analiza la forma urbana de las capitales provinciales de Castilla-La Mancha tanto para demostrar la validez del método Spacemate como para identificar, clasificar y analizar la forma urbana en ciudades medias.

Este artículo se estructura de la siguiente manera. En primer lugar se recoge el estado de la cuestión en el campo de las formas urbanas, mostrando los principales estudios de referencia tanto a nivel internacional como nacional. A continuación se expone la metodología seguida para la consecución de los objetivos. Posteriormente se presentan y discuten los resultados obtenidos, de los cuales se extraerán unas conclusiones.

\section{El estudio de la forma física urbana y sus implicaciones urbanísticas y socioeconómicas}

En base a diferentes obras de referencia sobre el estudio de la forma urbana a escala internacional e interdisciplinar (Morris, 1979, Kostof, 1991; Panerai et al., 1986; Moudon, 1994; 1997; Vernez, 1997; Conzen, 2001; Whitehand, 2001; Panerai et al., 2004; Gauthiez, 2004; Ruiz-Apilánez et al., 2017) se han identificado cuatro asuntos que ayudan a encuadrar y justificar la propuesta de investigación de este artículo: el estudio cuantitativo de las formas urbanas.

La noción de forma urbana. La forma o morfología urbana refiere al estudio físico de la forma urbana construida, de los agentes y procesos que le dan forma así como de sus interdependencias (Larkham, 2006; Capel, 2016). Los estudios de forma urbana han estado guiados por dos grandes objetivos: (a) descriptivos y/o explicativos; (b) normativos. Los primeros se centran en estudiar cómo las ciudades se han construido y han evolucionado. Más concretamente, analizan cómo el contexto social, económico, cultural... interacciona con el espacio físico de la ciudad, cómo lo produce, lo crea y lo modifica. Los segundos, focalizan su atención en el espacio físico de la ciudad y cómo interacciona e influye en la sociedad. La propuesta de investigación planteada en este artículo seguiría un objetivo de tipo normativo. 
Los enfoques y/o aproximaciones al estudio de la forma urbana. Éstos se relacionan con tres grandes escuelas: la anglosajona -Conzen, Whitehand...-, la italiana -Muratori, Canigia...-, y la francesa -Castex, Panerai...- (Moudon, 1997), a las que se podría añadir la española en base a la aportación de Solá-Morales, entre otros. La escuela anglosajona ha puesto énfasis en el estudio morfogenético del viario-parcelario-usos de suelo. Paralelamente a una consideración del parcelario como célula del plano urbano en relación directa con su entorno -trazado viario- y con su historia, Conzen (2001) considera la visión de la dinámica del parcelario como producto global de las transformaciones sociales que se producen en la ciudad y como contenedor de diferentes usos del suelo según épocas (Whitehand, 2001). La escuela italiana ha insistido en los aspectos formativos del tipo arquitectónico -estudios morfotipológicos-. El papel de la arquitectura más repetitiva se convierte en el elemento decisivo de explicación de los distintos tejidos constituyentes de la forma urbana. La escuela francesa presenta la manzana (y el tejido urbano) como principal elemento de análisis, pues es una unidad que ayuda a explicar tanto la estructura de la ciudad (configuración de la forma de la ciudad a través de manzanas) como el proyecto urbano (configuración de la forma en el interior de la manzana). La escuela española, destaca que a través de las formas infraestructurales de calles (urbanización), solares (parcelación) y casas (edificación) se pueden detectar diferentes combinaciones (o formas urbanas) que dan lugar a diferentes tejidos urbanos.

La buena forma física urbana. En el "Manifiesto por el Diseño Urbano", Appleyard y Jacobs (1984) plantean la necesidad de una reacción frente a los problemas de la ciudad actual (medio ambiente inhabitable, gigantismo y pérdida de control, privatización a gran escala y pérdida de la vida colectiva, fragmentación centrífuga, destrucción de lugares valiosos, pérdida del lugar, injusticia, etc.) en base a nuevos objetivos para la vida urbana: habitabilidad, identidad y control, aumento de oportunidades, autenticidad y significado, comunidad y vida colectiva, mejora del medio ambiente, nuevo tejido urbano, etc. En buena parte se trata de un intento de recuperación de la morfología y diseño de la ciudad preindustrial, o al menos de la ciudad compacta, incorporando la calidad habitacional de la ciudad moderna. Por ello, el conocimiento de las formas urbanas permite a los planificadores urbanos prever o identificar rápidamente las carencias, necesidades o dificultades de cada tipo de forma urbana, y actuar en consecuencia. Conociendo la forma física urbana de las ciudades se podrán resolver problemas ambientales, económicos o sociales.

La localización de las formas urbanas estudiadas. La mayor parte de los estudios sobre forma urbana han centrado su atención en las grandes ciudades y su periferia más inmediata dejando al margen las formas y las lógicas de crecimiento de ciudades medias y pequeñas así como de los municipios rurales (Zárate, 1998). En buena medida, esta mirada selectiva hacia determinados asentamientos estaría relacionado con la lógica de crecimiento y expansión de grandes ciudades y áreas metropolitanas durante el siglo XX. Así, surge la necesidad de desarrollar un sistema de identificación, clasificación y análisis de formas urbanas válido para ciudades 
medias y pequeñas, así como para municipios rurales, que sea objetivo y extrapolable a cualquier población, independientemente de su ubicación, tamaño o bagaje histórico.

\subsection{El origen del estudio de la forma urbana y el legado de Cervellati $y$ Scannavini (1969)}

La escuela italiana desarrolló los primeros estudios urbanos con fundamentos científicos a partir del trabajo de los arquitectos Cervellati y Scannavini para el "Plan para el centro histórico de Bolonia" en 1969. Este plan buscaba reavivar el centro histórico boloñés duramente castigado por la Segunda Guerra Mundial (1939-1945), carente de espacios libres y equipamientos y con una población envejecida y decreciente. Para ello se optó por realizar una rehabilitación sistemática del mismo manteniendo las tipologías, los tejidos y el funcionamiento tradicional de éste, es decir, el de una ciudad preindustrial, pero con los servicios y equipamientos contemporáneos. Para mantener la esencia identitaria del casco, Cervellati y Scannavini llevaron a cabo una metodología científica cuyo proceso partía de una extensa recogida de datos, un análisis exhaustivo y un diagnóstico tipológico final. Como resultado del mismo obtuvieron por primera vez cuatro formas urbanas con las que clasificaron todas las edificaciones del centro histórico (Blasco, 2014): Grupo A: Grandes conjuntos monumentales; Grupo B: Edificios complejos con patios; Grupo C: Edificios privados de vivienda obrera y artesana de entre los siglos XVI y XVIII; y Grupo D: Edificios tradicionales con variaciones de escala y tipo. Con el tiempo, lo que Cervellati y Scannavini llamaron "tipología" pasó a denominarse "forma urbana", y el estudio de la misma pasó de centrarse únicamente en el casco histórico a analizar la ciudad en su totalidad (Rodríguez-Tarduchy, 2011).

Pero el éxito del "Plan Bolonia" se basa no solo en estos minuciosos análisis del espacio físico, sino también en la idea de que la conservación de la forma urbana va directamente ligada a la conservación social. Cervellati y Scannavini hicieron gran énfasis en este aspecto promoviendo vivienda social, incrementando zonas verdes y equipamientos y fomentando la participación social a partir de los "Consigli di Quartiere".

\section{2. “Formas urbanasd: de la manzana al bloque”, de Philippe Panerai (1986)}

La escuela francesa está representada por el arquitecto y urbanista Philippe Panerai. En este caso, la atención se centra en el papel fundamental de la parcela construida como elemento generador de los tejidos urbanos. Su obra "Formas urbanas: de la manzana al bloque" analiza cuatro grandes actuaciones urbanas, y algunas más pequeñas del Estilo Internacional, que escenifican la evolución desde la ordenación a nivel de parcela, propia de la ciudad preindustrial, hasta la disolución de ésta y de la manzana.

En primer lugar, el París de Haussman (1853-1882) sustituye gran parte del viejo tejido medieval con grandes avenidas, monumentos y equipamientos, siguiendo siempre unos cánones de embellecimiento urbano clásicos. Los nuevos viarios 
alterarán las formas de las manzanas, muchas de las cuales pasarán a ser triangulares o trapezoidales, así como la parcelación existente, que se racionalizará. La edificación será en bloque. Con Haussmann la unidad de intervención en la ciudad pasará a ser la manzana, algunas de ellas con funciones específicas, como la manzana-equipamiento o la manzana-monumento, lo que unido a la especialización de barrios, supondrá el inicio de la zonificación en las ciudades europeas. El espacio público y el privado quedarán clara y rígidamente delimitados por la alineación. La manzana "haussmanniana" sigue estructurando la ciudad, por lo que es compatible con las preexistentes, pero su rigidez formal hizo que París fuese incapaz de acomodar los retos del crecimiento que se le plantearon a principios del siglo XX.

Como consecuencia del elevado crecimiento poblacional y la incapacidad técnica de crear asentamientos suburbanos adecuados, surgen las ciudades-jardín de Londres (1905-1925), promociones de vivienda privada basadas en una vuelta idealizada a la vida rural mediante la creación de comunidades independientes y autosuficientes con mezcla de estratos sociales en un entorno ajardinado, amplio y salubre. Rápidamente, la ciudad-jardín se convirtió en un barrio residencial de vivienda unifamiliar para clases medias y altas formado por agrupaciones de viviendas, pareadas o exentas, que disponen de un centro con equipamientos y comercio y unas zonas de trabajo, principalmente industrias, a su alrededor, pero alejadas del conjunto. Todo ello se desarrollaba en un ambiente bucólico con zonas ajardinadas, viarios jerarquizados y especializados y una clara separación ente lo público y lo privado. Con la ciudadjardín, la manzana pasa a ser el resultado de un viario poco estructurado que, debido a la privatización de espacios y la forma de vida, constituirá un mero espacio para la circulación.

Las expansiones de Ámsterdam (1913-1934) son el último gran ejemplo de urbanismo tradicional. Se caracterizaban por la construcción masiva de viviendas, la municipalización del suelo, la referencia a la ciudad existente, el gran peso de la arquitectura (se emplearon tipos arquitectónicos a imitación de los tradicionales, como el dúplex) y la planificación a largo plazo. Destacan las actuaciones de Spaarndammerbuurt (rehabilitación de un barrio obrero) y Ámsterdam Sur (expansión propiamente dicha). La unidad de promoción también fue la manzana, pero en este caso abiertas, el patio de las mismas estaba ajardinado y a éste daban los jardines y las entradas, principales o traseras, de las viviendas. Aunque el modelo tuvo un gran éxito, el hecho de abrir la manzana favoreció su desintegración en los años 30, cuando se desarrolló el Estilo Internacional y las manzanas de unifamiliares fueron sustituidas por bloques aislados de seis pisos o más.

El gran crecimiento demográfico de Frankfurt entre 1925 y 1930, unido al parón en la construcción después de la Primera Guerra Mundial, llevó a la ciudad a desarrollar un ambicioso plan de reordenación y construcción de vivienda pública del que se encargó Ernst May, figura destacada del Estilo Internacional. Así se desarrollan un conjunto de tres actuaciones de barrios satélites que siguen el Estilo Internacional y se separan de Frankfurt por un cinturón verde, promoviéndose la especialización y la zonificación. Las formas edificatorias evolucionarán desde el unifamiliar o el dúplex hasta el edificio en bloque de las últimas intervenciones. La 
manzana también evoluciona con el desarrollo de las obras, pasando de manzana cerrada con patios interiores privados a una manzana abierta con zonas verdes públicas, edificios exentos o laminares y atravesada por viarios o pasos especializados (peatonales o rodados). La manzana de Frankfurt pasa a ser una agrupación de edificios normalizados y unos viales que se organizan según una lógica abstracta que hace que el entorno, pierda su realidad.

Finalmente, la concepción de Le Corbusier de la ciudad ideal, la "Ciudad Radiante" consistía en un conjunto de torres aisladas sobre un tapiz de césped, dispuestas según criterios de higiene y soleamiento, por el que trascurren las vías de comunicación segregadas en función del usuario, peatón o vehículo. La ciudad perfecta debía estar completamente zonificada y el tipo edificatorio ideal era el edificio colectivo en bloque. Le Corbusier propone el fin de la manzana tradicional y su sustitución por la manzana vertical, es decir, el propio edificio es la manzana, con accesos, comercio y equipamientos en galerías interiores. Fuera de éste sólo se ubicarían los espacios libres, que serían las zonas verdes exteriores a los edificios.

\section{3. “Las formas de crecimiento urbano”, de Manuel de Solà-Morales (1997)}

En cuanto a la escuela española, el estudio de la forma urbana está representado por autores como Solá-Morales (1997) o Rodríguez-Tarduchy (2011), así como Capel (1975; 2006), Moneo (1982), López de Lucio (1996; 1997), Vilagrasa (1998), Cebrián y Panadero (2013) o Ruiz-Apilánez et al. (2017), entre otros.

En "Las formas de crecimiento urbano", el arquitecto, urbanista y sociólogo Manuel de Solà-Morales y Rubió, analiza la evolución de las distintas formas urbanas que se dan durante el crecimiento de Barcelona, desde el siglo XIX al XX. Esta obra pone énfasis en el estudio de la historia del crecimiento de la ciudad, en las relaciones entre localización y espacio social y en el planeamiento. Para Solà-Morales, el planeamiento y las ordenanzas municipales son los que determinan la construcción de la ciudad y la tipología edificatoria.

Tabla 1. Tipologías o formas urbanas según Solà-Morales (1997).

\begin{tabular}{|c|c|c|c|c|}
\hline \multirow{2}{*}{$\begin{array}{l}\text { Proceso } \\
\text { Ensanche }\end{array}$} & \multirow{2}{*}{$\begin{array}{l}\text { Reconocido } \\
\text { SI }\end{array}$} & \multicolumn{3}{|c|}{ Orden de operación $\left(1^{\circ}, 2^{\circ}\right.$ y $\left.3^{\circ}\right)$} \\
\hline & & $\mathrm{P}$ & $\mathrm{U}$ & $\mathrm{E}$ \\
\hline Crecimiento Suburbano & SI & $\mathrm{U}$ & $\mathrm{P}$ & $\mathrm{E}$ \\
\hline Polígono & SI & PUE & - & - \\
\hline Ciudad Jardín & SI & UP & $\mathrm{E}$ & - \\
\hline Barraca & $\mathrm{NO}$ & - & $\mathrm{E}$ & - \\
\hline Invasión & NO & $\mathrm{P}$ & - & - \\
\hline Urbanización marginal & $\mathrm{NO}$ & $\mathrm{P}$ & $\mathrm{E}$ & - \\
\hline
\end{tabular}

Fuente: Elaboración propia. 
El proceso de crecimiento urbano se define como el conjunto de operaciones materiales de construcción de la ciudad. Estas operaciones son: la parcelación (P) o transformación de suelo rústico en urbano; la urbanización (U) o construcción de los elementos físicos colectivos de la ciudad; y la edificación (E) o construcción de la parte edificada. Las tipologías urbanas quedan clasificadas en función de si están o no recogidas por el planeamiento (ver Tabla 1).

El ensanche es una forma de generar ciudad ideada en el siglo XIX por el ingeniero español Ildefonso Cerdà. Estaba diseñado para la burguesía y basado en criterios de higiene y movilidad. El ensanche se basa en unos planos de ordenación y trazado a partir de los cuales se desarrollará por medio de la iniciativa privada. La unión con la ciudad existente es por medio de rondas, plazas y vías de penetración. El tipo edificatorio del ensanche es variable. En los ensanches de grandes ciudades suele ser la edificación en altura entre medianeras concentrada en el perímetro de la manzana y con patio central, mientras que en los ensanches de pequeñas poblaciones la edificación es de pocas alturas y ocupa toda la manzana.

El crecimiento suburbano es propio de pequeños municipios o de las periferias de ciudades medias y grandes donde se producen reparcelaciones de terrenos rurales en los que a veces el propietario del mismo es el promotor. El viario suele ser regular, aunque depende de la ubicación, y estar estructurado en torno a una plaza central. Es común que se apoye en caminos existentes. La vivienda es unifamiliar o colectiva en baja altura, ambos entre medianeras, con patio interior y doble ventilación. Algunos bajos suelen emplearse para actividades económicas y se tiende a la densificación de la parcela. Si la vivienda es autoconstruida, el desarrollo suburbano pasa a ser urbanización marginal.

Los polígonos de vivienda son promociones de vivienda cuya principal finalidad es crear barrios de calidad, higiénicos y económicos para las clases trabajadoras. Los polígonos son resultado de proyectos y actuaciones unitarias, lo que genera crecimientos por paquetes cerrados con segregación, bordes discontinuos y monotonía interior. Existen dos tipos de polígonos. Los polígonos de vivienda unifamiliar surgen con la Ley de Casas Baratas (1921). Son barrios pequeños de baja densidad con calles regulares y cruces ortogonales donde se repite un tipo edificatorio unifamiliar. Suelen disponer de plaza con equipamientos. Los polígonos de vivienda colectiva están basados en el Estilo Internacional y surgen tras el fin de la Guerra Civil (1936-1939). Su tamaño, altura y densidad van creciendo con el tiempo a la vez que se construyen cada vez más alejados de la ciudad. El tipo edificatorio fue en un principio el edificio laminar para sustituirse posteriormente por el edificio en bloque exento o adosado.

La ciudad jardín, surgida como una modificación de las teorías de Unwin, es una forma de crecimiento unifamiliar autónoma, es decir, fuera del alcance de la ciudad y de los no-residentes. Su edificación es unifamiliar, aislada o agrupada en pequeños conjuntos. El viario es irregular y sinuoso en origen, rodeado de vegetación y, en algunos casos, carente de acerado. Es adaptable a topografías y terrenos muy diversos.

La barraca es un desarrollo ilegal de viviendas de escasa calidad y carente de servicios en terrenos ajenos, que pueden ser complicados para la edificación. El viario 
es el residuo que no queda edificado y el tipo edificatorio es la chabola. Las barracas suelen eliminarse para realojar a sus inquilinos en viviendas de mayor calidad, habitualmente en polígonos de vivienda colectiva.

La urbanización marginal se desarrolla fuera de los mecanismos de la ciudad por medio de la autoconstrucción de viviendas en un suelo rural reparcelado. El viario es regular, ortogonal y escaso, pues es una parte que no aporta beneficios, por ello las calles son muy largas y estrechas. Estas zonas carecen de equipamientos y servicios en su inicio, que se llevarán con posterioridad. Las viviendas son unifamiliares que se adaptan a las necesidades de cada familia, suelen disponer de patio trasero y mejorarse a medida que mejora la renta de sus propietarios. El destino de estos barrios puede ser la congelación, la prohibición de modificaciones, la remodelación, la adaptación a la ciudad (con reparcelaciones y urbanizaciones) o la continuación del proceso de mejora.

\section{4. "Forma y Ciudad. En los límites de la arquitectura y el urbanismo", de María José Rodríguez-Tarduchi (2011)}

En "Forma y ciudad: en los límites de la arquitectura y el urbanismo", la arquitecta Rodríguez-Tadurchi sigue la estela de Solà-Morales, pero desde una perspectiva más genérica. Esto le permite hallar patrones de carácter general que definen una serie de formas urbanas identificadas en sus estudios.

Los cascos antiguos son el resultado de la superposición del tejido medieval, renacentista y barroco. La delimitación entre lo público y lo privado queda claramente definida por la fachada. Es un modelo de alta densidad y de homogeneidad tipológica. $\mathrm{Su}$ tipo edificatorio es el caserío, edificio de poco frente y gran fondo con hasta 4 plantas o incluso 6 en terrenos accidentados. También hay edificios singulares como palacios, religiosos o políticos. Las parcelas son variables, con mucho fondo, poco frente y con patios densificados. Las manzanas, que también carecen de patio, son irregulares y responden a trazados espontáneos, radiales, de caminos o a aperturas realizadas en siglos posteriores. El viario es estrecho e irregular, por su carácter radiocéntrico y por ajustarse al terreno, y además se encuentra jerarquizado. Destacan los caminos preexistentes o los que van, o iban, a las puertas de las murallas. La calle es continua debido a la continuidad de la fachada. Finalmente, los centros históricos carecen de zonas verdes, espacios abiertos, que suelen ser plazas de iglesias y/o mercados, y equipamientos.

Las viviendas unifamiliares son desarrollos extensivos y dispersos de baja densidad. Su origen son las ideas de Unwin, pero con la llegada del Estilo Internacional se densificaron y los viarios pasaron a ser rectos y regulares. En España se dan cuatro tipos de unifamiliares: los unifamiliares desarrollados dentro de parcelas independientes de la ciudad construida como una edificación más; las colonias jardín (1920-1935), que se desarrollaron en el extrarradio de las ciudades para clases altas o bajas, pero no mezcladas, y que acabarían absorbidas por la ciudad; las urbanizaciones periféricas en entornos valiosos (1960-1970), que eran desarrollos burgueses de baja densidad, grandes parcelas y equipamientos; y los nuevos 
ensanches (1985-), que son los unifamiliares propios de las periferias de las ciudades contemporáneas, pudiendo convivir con tipos más densos, como bloques de vivienda. Los tipos edificatorios son el adosado (10-30 hab/ha), el pareado (10-17 hab/ha) y el exento o aislado (1-17 hab/ha). Las parcelas son, por lo general, pequeñas, rectangulares y con retranqueo, aunque en los tipos aislados pueden ser de varias hectáreas. Las manzanas dependen del viario, pueden ser rectangulares o irregulares y disponer de fondos de saco. El viario varía en función de la localización de los unifamiliares, en la ciudad es regular, recto y jerárquico, con el vallado de los unifamiliares determinando la alineación, mientras que en zonas periféricas es irregular y sinuoso. Los espacios libres varían en función del año de construcción: en los primeros desarrollos eran plazas y zonas ajardinadas, en la actualidad son zonas lineales y de juegos infantiles.

Las edificaciones exentas se basan en las ideas de Le Corbusier. Son edificios en altura aislados sobre zonas ajardinadas comunes. Los tipos edificatorios empleados pueden ser en bloque lineal, bloque en galería, bloque con corredor interior o bloque en "H". Las parcelas y las manzanas no existen, ya que han sido sustituidas por el polígono, conjunto de edificios aislados con zonas verdes comunes abiertas. En la actualidad muchas manzanas son el bloque mismo, pues los vecinos han cedido las zonas comunes a los consistorios para no mantenerlas. El viario, regular y jerarquizado, puede ser estructurante (viario perimetral y tangente al polígono) o local (que da acceso a garajes y aparcamientos). Finalmente, los espacios libres suelen ser de baja calidad y estar dispuestos en zonas poco propicias. Su proporción es extremadamente elevada (65-75\%) y suelen atraer actividades marginales.

Los nuevos ensanches son desarrollos de vivienda en bloque que surgieron a partir de 1980 como respuesta a los problemas del polígono de vivienda exenta. Recuperan características de los ensanches decimonónicos (manzana cerrada, cruces ortogonales, bulevares...), así como la calle-corredor y la alineación como separación pública/privada. Se construyeron en nuevos desarrollos y en huecos entre la ciudad y los polígonos. Sus tipos edificatorios son las manzanas cerradas en bloque perimetral de doble crujía, el doble bloque perimetral, y los bloques en "U" o en "L". En esta forma urbana tampoco hay parcelas, ya que la unidad de promoción es la manzana, que es variable para adaptarse al viario. En su interior suelen disponer de zonas comunes. El viario está jerarquizado según capacidad y simbolismo, soliendo estar sobredimensionado. Destacan las vías de conexión con la ciudad existente, las calles perimetrales y los bulevares y avenidas. También hay vías peatonales y colectoras del tráfico interior. Los espacios libres y las zonas verdes son numerosos, destacan las plazas, las zonas lineales y los espacios de juego. Pero la falta de población residente, unida a la presencia de zonas comunes privadas, hace que estén en desuso.

\section{Metodología}

Tras un análisis en profundidad de las clasificaciones sobre las formas urbanas se observa que los trabajos realizados son subjetivos y de muy difícil extrapolación a 
otras ciudades. El objetivo principal de este artículo es profundizar en un método de identificación, clasificación y análisis de las formas urbanas, basado en datos objetivos, parámetros urbanísticos, indicadores de forma y medidas de dimensiones de la manzana y las parcelas, que lo hagan independiente del tamaño, localización y evolución histórica de la ciudad donde se aplique. Para ello, se ha recurrido al método Spacemate, desarrollado principalmente para la ciudad de Ámsterdam (Berghauser y Haupt, 2009), pero que en este caso se ha adaptado y aplicado a las capitales provinciales de Castilla-La Mancha. La información necesaria se ha obtenido de Catastro con fecha junio de 2015, tanto tabulada como georreferenciada, para calcular los parámetros urbanísticos de cada ciudad (Romero et al., 2014).

El método Spacemate se basa en la premisa de que la densidad y la distribución espacial del tejido de la ciudad determina su forma urbana, permitiendo analizarla de forma objetiva desde la escala de la edificación -con más interés arquitectónico-, hasta la de la ciudad o el conjunto de barrios (Berghauser y Haupt, 2009). Este método puede analizar edificios, parcelas, manzanas, sectores/barrios o ciudades enteras, aunque son los sectores o conjuntos de manzanas los más útiles para analizar las formas urbanas. El Spacemate se compone de dos elementos principales (ver Figura 1): la gráfica Spacemate propiamente dicha, que relaciona los parámetros GSI, FSI, las alturas y los espacios abiertos, permitiendo determinar la forma urbana de forma básica; y el diagrama $\mathbf{N}$, que permite conocer los anchos de calle, el porcentaje de espacio sin edificar y la densidad del viario. Con él la forma urbana está completamente definida.

La gráfica Spacemate se obtiene de la combinación de cuatro parámetros urbanísticos. Las abscisas corresponden con la ocupación del sector (GSI; relación entre la superficie construida en planta y la superficie del sector), y las ordenadas, con la edificabilidad (FSI; relación entre el área construida en todas las plantas de las edificaciones incluidas en el sector y el área del mismo). Dentro del cuadrante definido por la edificabilidad y la ocupación se representa el número medio de alturas de la edificación (L) y la presión de los espacios abiertos (OSR; relación entre el espacio no construido y el construido). Las diferentes alturas y OSRs deben representarse dentro del cuadrante en función de las características de los elementos a analizar, aunque como estándar se grafican entre 12 y 14 alturas y una variación de OSR desde 0.1 hasta 2 o 3 (García, 2013). Así se obtiene un gráfico donde puede accederse con dos de los cuatro datos que los componen y obtener inmediatamente los otros. Además, los cuatro parámetros delimitan un conjunto de zonas que corresponden con diferentes formas urbanas.

El diagrama $\mathbf{N}$ es el resultado de relacionar tres parámetros correspondientes a los espacios vacíos, el viario y el tejido urbano. Las abscisas del diagrama $\mathrm{N}$ corresponden con el ancho medio de calle (b), que se calcula en función de la densidad de viario $(\mathrm{N})$ y la tara ( $\mathrm{T}$; relación entre la superficie de espacios libres y la superficie total). El diagrama $\mathrm{N}$ sólo se emplea para agrupaciones de manzanas o sectores, pero en el segundo caso los grandes espacios abiertos así como las grandes vías de comunicación deben considerarse como áreas ocupadas para el cálculo de la tara. El dia- 
grama $\mathrm{N}$ determina cualquiera de sus parámetros $(\mathrm{b}, \mathrm{N}, \mathrm{T})$ en función de los otros dos y permite clasificar el tejido en función de su densidad de viario, el ancho del mismo y la longitud media de manzana (w), que depende de la densidad de viario.

Figura 1. Gráfica Spacemate y Diagrama N.

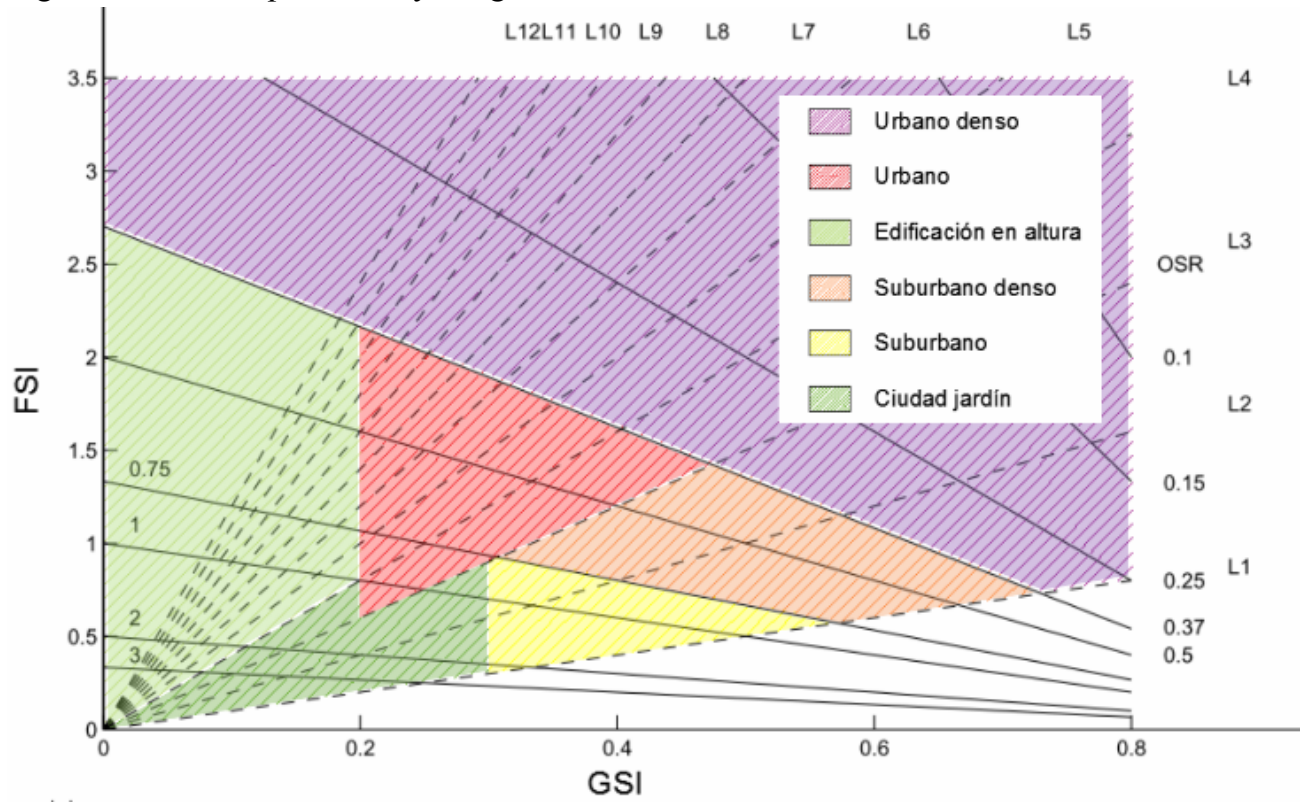

Variación de la trana urbana en función de la pasición dentro del Diagrama $N$

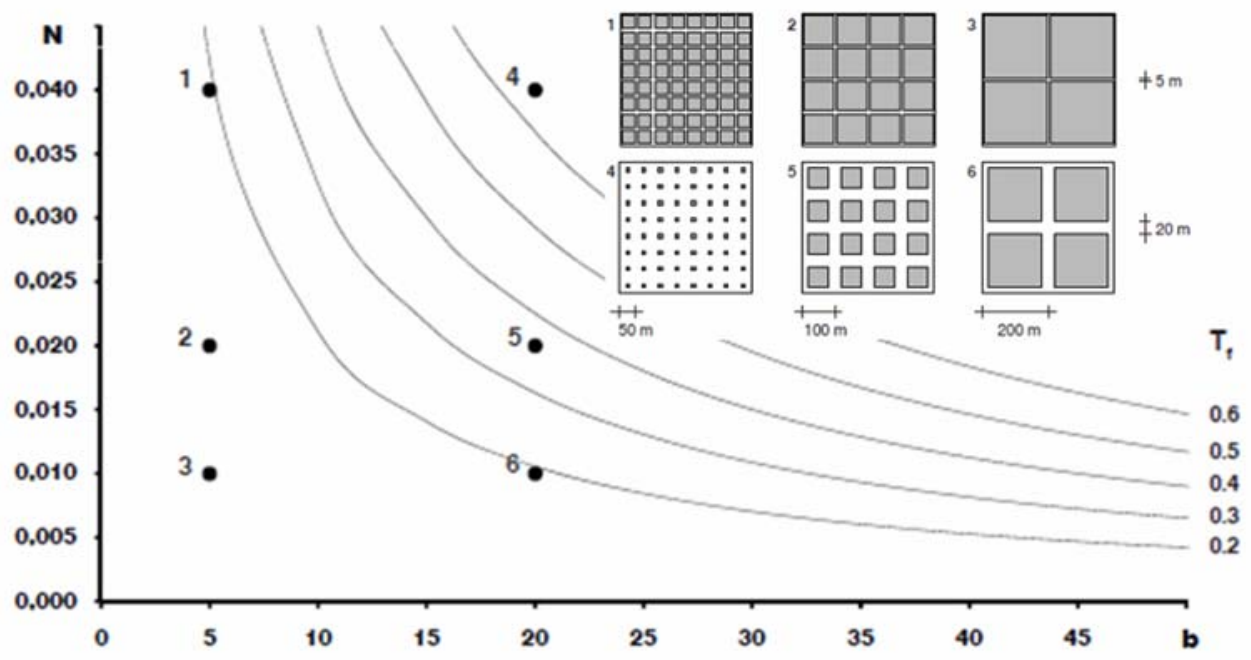

Fuente: Berghauser y Haupt (2009) 
El principal inconveniente del método Spacemate y del Diagrama N es que la exactitud de ambos decae en gran medida cuando el tejido analizado es heterogéneo, ya que los puntos resultantes son medias de los parámetros de edificaciones que, aunque en un mismo entorno, pueden ser muy diferentes entre sí (Berghauser y Haupt, 2009). Debido a esto, la selección del área de aplicación para ambos gráficos, que debe ser la misma, es un proceso complicado. Algunos autores solventan el problema de selección del área de aplicación empleando secciones censales redelimitadas para evitar que incluyan elementos que distorsionen los resultados, como ríos o vías de ferrocarril (García, 2013). No obstante, las secciones censales tienen una finalidad estadística pero no urbanística, e incluyen en una misma área formas urbanas que pueden ser muy diversas, por lo que el problema de pérdida de exactitud se mantiene. Para superar este problema, Hernández-Aja (1997), en su estudio de barrios vulnerables en España, propone una clasificación de áreas homogéneas. Estas áreas se delimitan a partir de un método de trabajo desarrollado en cinco fases: análisis del estudio sociodemográfico, determinación de los ámbitos sobre el plano de secciones censales, entrevista con la administración municipal, trabajo de campo, y revisión estadística de las delimitaciones propuestas. Este artículo propone determinar mediante fotografía aérea zonas de manzanas de características urbanas similares que después servirán de áreas de trabajo para los gráficos Spacemate y Diagrama N. Por tanto, la unidad básica de trabajo es la manzana, ya que la determinación de la forma urbana para unidades menores (parcelas o edificaciones) tiene interés arquitectónico, pero escaso interés urbanístico (Berghauser y Haupt, 2009).

\subsection{Estudio de casos}

Albacete es la ciudad más poblada de toda Castilla-La Mancha (ver Tabla 2), con más del doble de población que el segundo (Talavera de la Reina). Su población se encuentra repartida en una superficie urbana de unos $27,71 \mathrm{~km}^{2}$, por lo que la densidad media de la zona construida es de 62,11 hab/ha. Debido a esta extensión, se analizaron un total de 16 zonas (ver Figura 2). Guadalajara ha sido la capital castellanomanchega que más ha crecido en los últimos años, contando actualmente con 83.391 habitantes en un área urbana de $19,94 \mathrm{~km}^{2}$, que le proporcionan una densidad de 41,82 hab/ha. Debido a su extensión y a la claridad de las zonas identificadas se han analizado otras 16 zonas (ver Figura 3). Toledo es la capital regional y su población es de 83.226 habitantes, repartidos en $66,44 \mathrm{~km}^{2}$, ofreciendo la menor densidad de todas las capitales. Debido a su gran extensión urbana, en Toledo se han analizado 18 zonas (ver Figura 4). Por su parte, Ciudad Real tiene 74.427 habitantes dentro de un recinto urbano de $19,72 \mathrm{~km}^{2}$, lo que le proporciona una densidad de 37,90 hab/ha. Debido a la clara distribución de las zonas y a la multitud de pequeñas promociones singulares, se han analizado 17 zonas (ver Figura 5). Finalmente, con sólo 55.428 habitantes, Cuenca es la capital más pequeña de todas, con una superficie urbana de tan solo $11,87 \mathrm{~km}^{2}$ y una densidad de $46,70 \mathrm{hab} / \mathrm{ha}$. Su baja superficie urbana, unida a sus pequeñas promociones, ha hecho que sólo se hayan considerado 13 zonas (ver Figura 6). 
Tabla 2. Tabla resumen de las capitales provinciales de Castilla-La Mancha

\begin{tabular}{lcccc}
\hline & Población en 2015 & Sup. urbana $\left.\mathbf{( k m}^{2}\right)$ & Densidad (hab/ha) & Zonas analizadas \\
\hline Albacete & 172.121 & 27,71 & 62,11 & 16 \\
\hline Guadalajara & 83.391 & 19,94 & 41,82 & 16 \\
\hline Toledo & 83.226 & 66,44 & 12,53 & 18 \\
\hline Ciudad Real & 74.427 & 19,72 & 37,90 & 17 \\
\hline Cuenca & 55.428 & 11,87 & 46,70 & 13 \\
\hline
\end{tabular}

Fuente: Elaboración propia.

\section{Resultados}

Tras aplicar el método desarrollado a las capitales provinciales de Castilla-La Mancha (ver Tabla 3 y Figuras 2-6), se observa que la ciudad más densa de todas es Cuenca, con una intensidad de edificación o FSI de 1,45. Es decir, Cuenca alcanza el nivel más alto de edificabilidad que la normativa permite, unido al hecho de que es la ciudad con menos nuevos desarrollos de vivienda unifamiliar, que reducen drásticamente la media, como en el caso de Toledo. Seguidamente encontramos Albacete (FSI 1,29) por su elevada ocupación (GSI), y Toledo (FSI 1,19) por su número de alturas (L) y amplia "espaciosidad" (OSR) debido a los unifamiliares y a la edificación exenta. La edificabilidad en Guadalajara se debe también al número de alturas medias (casi 4). La GSI u ocupación es similar en todas las ciudades. Esto es debido a que todas las capitales provinciales presentan un casco histórico o centro urbano con una ocupación (superficie construida en planta) elevada y unas promociones periféricas menos ocupadas.

En cuanto a las alturas (L), la ciudad más elevada es Guadalajara, con una media de casi 4 plantas, si bien todas las demás superan o están cerca de 3 . Este elevado número de alturas es debido a las numerosas promociones de edificación exenta y a las elevadas promociones de unifamiliares, que rozan las 3 alturas.

Respecto a la "espaciosidad" (relación entre espacio no construido y el construido), la menor OSR es la de Albacete, debido a su alta GSI y a la falta de espacios urbanos abiertos; si bien todos los centros de las ciudades presentan OSRs muy bajos, menos Guadalajara. El caso de Albacete es debido a que concentra los espacios abiertos en grandes zonas que no han sido analizadas, mientras que Guadalajara dispone de muchas plazas desperdigadas por todo el centro y zonas periféricas extensas. Los casos de Cuenca y, sobre todo, Toledo son especialmente singulares, ya que la OSR media oculta dos realidades opuestas. La OSR media de ambos es medianamente elevada por la presencia de promociones de unifamiliares periféricos muy poco densificados, pero ambas ciudades, y en especial sus centros, presencian una evidente carencia de espacios urbanos abiertos. Asimismo, se puede apreciar cómo los parámetros del Diagrama $\mathrm{N}$ son similares para las cinco ciudades (ver Tabla $3 \mathrm{y}$ Figuras 2-6). Destacan Toledo y Cuenca con las densidades de viario $\mathrm{N}$ más elevadas 
que el resto, lo que provoca que sus calles sean más estrechas. Obviamente, esto es debido a la gran extensión de sus cascos históricos y de los arrabales de los mismos. El caso de Albacete es curioso, pues su $\mathrm{N}$ es media y el ancho de sus parcelas es muy bajo (w). Esto es debido a la abundante presencia de torres exentas de pequeño tamaño. Por su parte, las taras (T; relación entre la superficie de espacios libres y la superficie total de la zona) son en todos los casos medias-bajas, debido a que en las ciudades españolas predomina lo privado frente a lo público, especialmente en los centros. No obstante, se observa cómo Albacete presenta una tara superior, mientras que Guadalajara es la que menor tara tiene.

Tabla 3. Valores medios de las Spacemate y de los Diagramas N.

\begin{tabular}{|c|c|c|c|c|c|c|c|c|}
\hline & FSI & GSI & $\mathbf{L}$ & OSR & $\mathbf{N}\left(\mathbf{m} / \mathbf{m}^{2}\right)$ & $\mathbf{T}$ & b (m) & w (m) \\
\hline Albacete & 1,29 & 0,43 & 3,01 & 0,61 & 0,0277 & 0,42 & 17,60 & 74,33 \\
\hline Guadalaja & 1,17 & 0,31 & 3,98 & 0,79 & 0,0250 & 0,35 & 16,91 & 90,44 \\
\hline Toledo & 1,19 & 0,36 & 3,33 & 1,24 & 0,0326 & 0,36 & 14,27 & 87,47 \\
\hline Ciudad R & 1,10 & 0,37 & 2,99 & 0,92 & 0,0251 & 0,37 & 18,10 & 92,13 \\
\hline Cuenca & 1,45 & 0,40 & 3,55 & 0,82 & 0,0316 & 0,38 & 17,97 & 79,10 \\
\hline
\end{tabular}

Fuente: Elaboración propia.

La Spacemate de Albacete (ver Figura 2) muestra que la ciudad es densa, tanto en horizontal como en vertical, predominando el lleno frente al hueco; y que está compuesta por tres formas urbanas predominantes claramente diferenciadas. (1) La zona morada (urbano denso), que se subdivide en el casco propiamente dicho, con una GSI de 0,6 y un número de alturas de 4, y las zonas periféricas densificadas (urbanizaciones "marginales" muy densificadas pero poco parecidas al casco y expansiones con un alto grado de sustitución muy similar al casco pero con menos alturas). (2) La zona amarilla (suburbano) de unifamiliares (antiguos o contemporáneos), con una GSI de 0,4 y 1,5 alturas medias. Los parámetros urbanísticos son prácticamente los mismos, una 1,5 alturas y unos 0,4 de GSI. Esta agrupación permite observar cómo todos los unifamiliares de Albacete se han construido en función de unos parámetros constantes en el tiempo. (3) La zona roja (urbano) corresponde con las promociones del Estilo Internacional, todas ellas demasiado bajas y, sobre todo, demasiado densas como para ser consideradas como edificación exenta.

Guadalajara ha conservado la esencia de su casco histórico, aunque también ha sufrido bastantes procesos de renovación y sustitución (ver Figura 3). Las zonas densas se concentran al sur y son promociones de edificaciones en altura apoyadas sobre la carretera. La zona más contemporánea, se encuentra al este y está compuesta por extensas promociones de unifamiliares con generosos jardines. Así, Guadalajara es una ciudad donde la densidad se reparte y no destacan zonas con excesos ni defectos acusados de ésta. En este caso las distintas partes de la ciudad no se diferencian de forma muy clara. (1) El grupo más evidente son los unifamiliares 
extensos, en verde oscuro. Se caracterizan por ser muy elevados, más de 3 plantas, y poco densos. Son la forma de crecimiento contemporáneo predominante de Guadalalajara y se concentran en el Noreste. (2) Las zonas de edificaciones exentas y nuevos ensanches, con densidades bajas y más de 4 alturas (algunos más de 7). (3) El casco histórico, en la frontera entre el urbano y el urbano denso, debido a que ha respetado los volúmenes originales de éste, presentando unas densidades más reducidas. (4) Elementos singulares, como una gran promoción de unifamiliares contemporáneos densos y elevados, y un crecimiento suburbano en las proximidades de la estación de ferrocarril.

Como en el caso de Guadalajara y Cuenca, Toledo ha respetado su casco histórico, por lo que ha crecido horizontalmente (ver Figura 4). Así, alrededor del casco se extienden promociones de polígonos de viviendas construidas cuando éste no pudo compactarse más, y más allá de éstos, unifamiliares de distinta índole, de menor densidad a medida que aumenta la renta de sus residentes. Se aprecian tres zonas muy claras: (1) El casco histórico, con una GSI muy alta y una FSI elevada, debido a la colmatación del recinto medieval. (2) Los unifamiliares extensos, promociones de vivienda de 1 o 2 alturas y de GSI baja o muy baja, concentrados en el oeste (Palomarejos y Cigarrales). (3) Las edificaciones exentas y nuevos ensanches (Buenavista y Avenida de Europa), situados en la periferia noroccidental de Toledo, con alturas y densidades bajas.

La Spacemate muestra que Ciudad Real es una ciudad de contrates (ver Figura 5). Por un lado se encuentra (1) la zona de intrarrondas o casco, densa y alta, con pocos espacios abiertos y que ha experimentado un fuerte proceso de sustitución, sobre todo en el centro, de unifamiliares por edificios en bloque. Por otro lado, la zona periférica, con promociones de polígonos de vivienda unifamiliar densa, unifamiliares adosados o viviendas "marginales", todos ellos de pocas alturas y bastante densificados; y las nuevas promociones de unifamiliares pareados y extensos que se concentran en el oeste, ligeramente más altos que los densos y su ocupación es mucho menor debido a los grandes jardines. Finalmente, tanto dentro como fuera de rondas, encontramos polígonos de vivienda del Estilo Internacional, muy densos para su tipología, y muy bajos, ya que los edificios no son muy elevados y la presencia de equipamientos disminuye la altura media.

Finalmente, el casco histórico Cuenca y las urbanizaciones históricas de arrabales marginales se han mantenido intactas gracias al escaso crecimiento poblacional (ver Figura 6). Pero cuando la ciudad comenzó a crecer a partir de mediados del siglo XX, la densificación de estas zonas se descartó para centrar el crecimiento en los alrededores de las mismas. Este crecimiento fue muy denso, por lo que en los últimos años las promociones más atractivas fueron los unifamiliares y las urbanizaciones colectivas de la periferia que ocupan casi dos tercios de la zona construida de la ciudad. Podemos ver que no hay zonas tan claras como en los casos anteriores. Aparte del (1) casco histórico, que no es muy denso por la presencia de plazas, destaca el (2) casco contemporáneo desarrollado a lo largo de la carretera (N-320a), extremadamente denso y de unas 5 alturas de media. (3) Las edificaciones exentas son el grupo más homogéneo, con unas 4,5 alturas y una ocupación o GSI de 0,3. (4) 
Los unifamiliares se dividen en tres zonas: los antiguos, en naranja, que son edificaciones marginales en las colinas de Cuenca; los pareados y aislados, en verde, que son promociones contemporáneas de baja densidad y baja altura (entre 1 y 2 plantas); y los adosados contemporáneos, en amarillo, de densidad intermedia pero más altos, con unas 2,5 plantas de media.

Figura 2. Zonas seleccionadas del municipio de Albacete, Spacemate y Diagrama N.
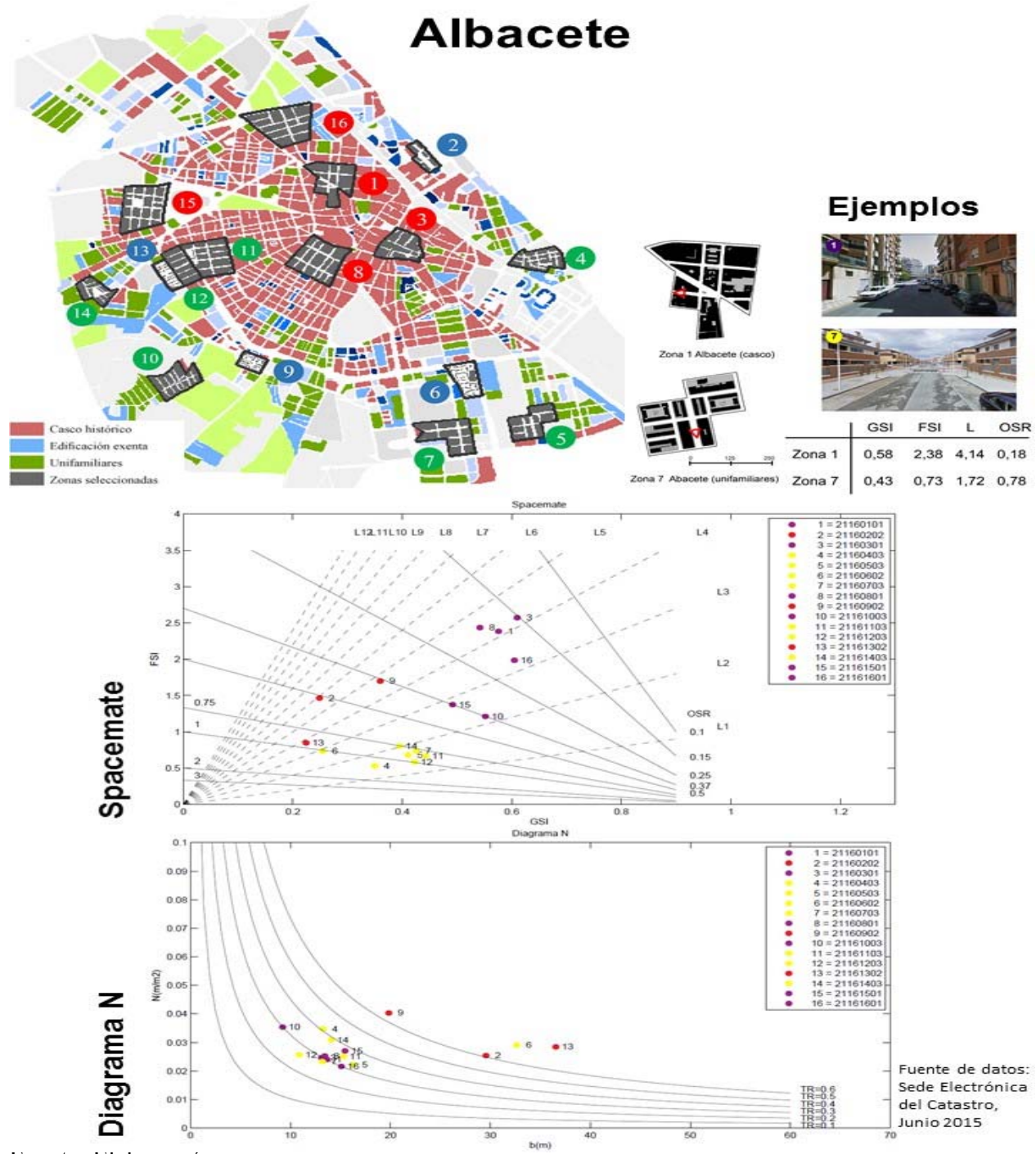

Fuente: Elaboración propia. 
Figura 3. Zonas seleccionadas del municipio de Ciudad Real, Spacemate y Diagrama N.

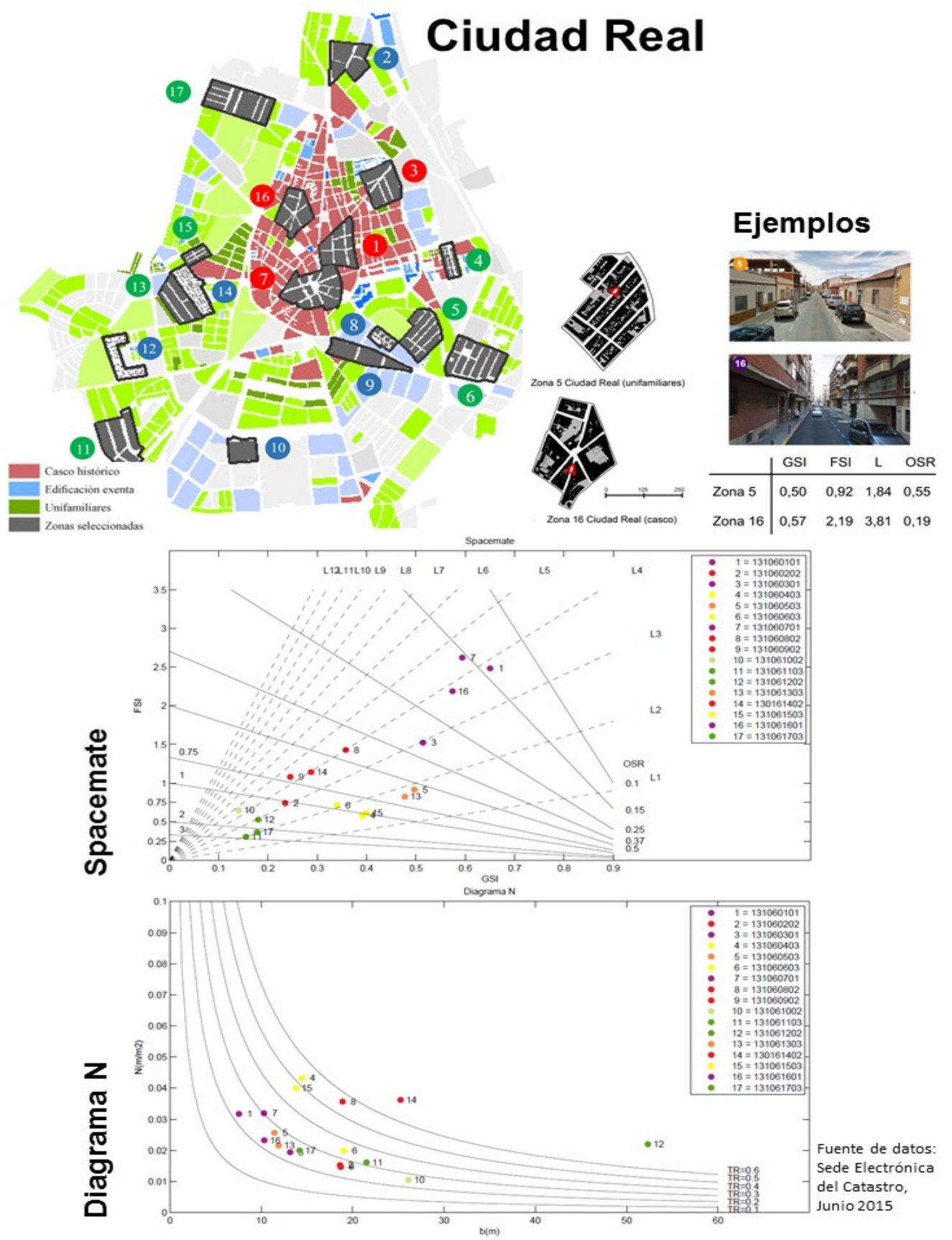

Fuente: Elaboración propia. 
Figura 4. Zonas seleccionadas del municipio de Cuenca, Spacemate y Diagrama N.

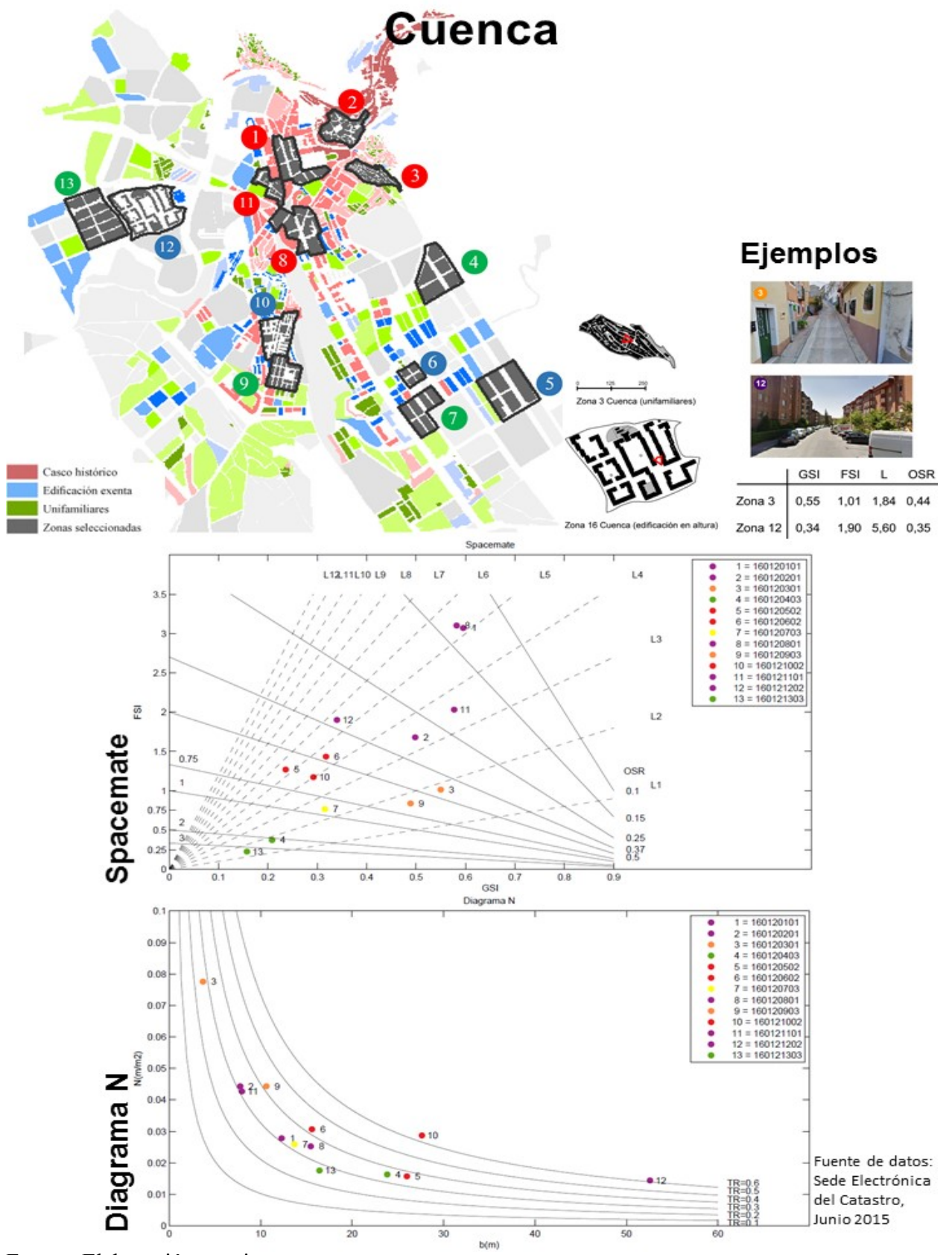

Fuente: Elaboración propia. 
Figura 5. Zonas seleccionadas del municipio de Guadalajara, Spacemate y Diagrama N.

\section{Guadalajara}

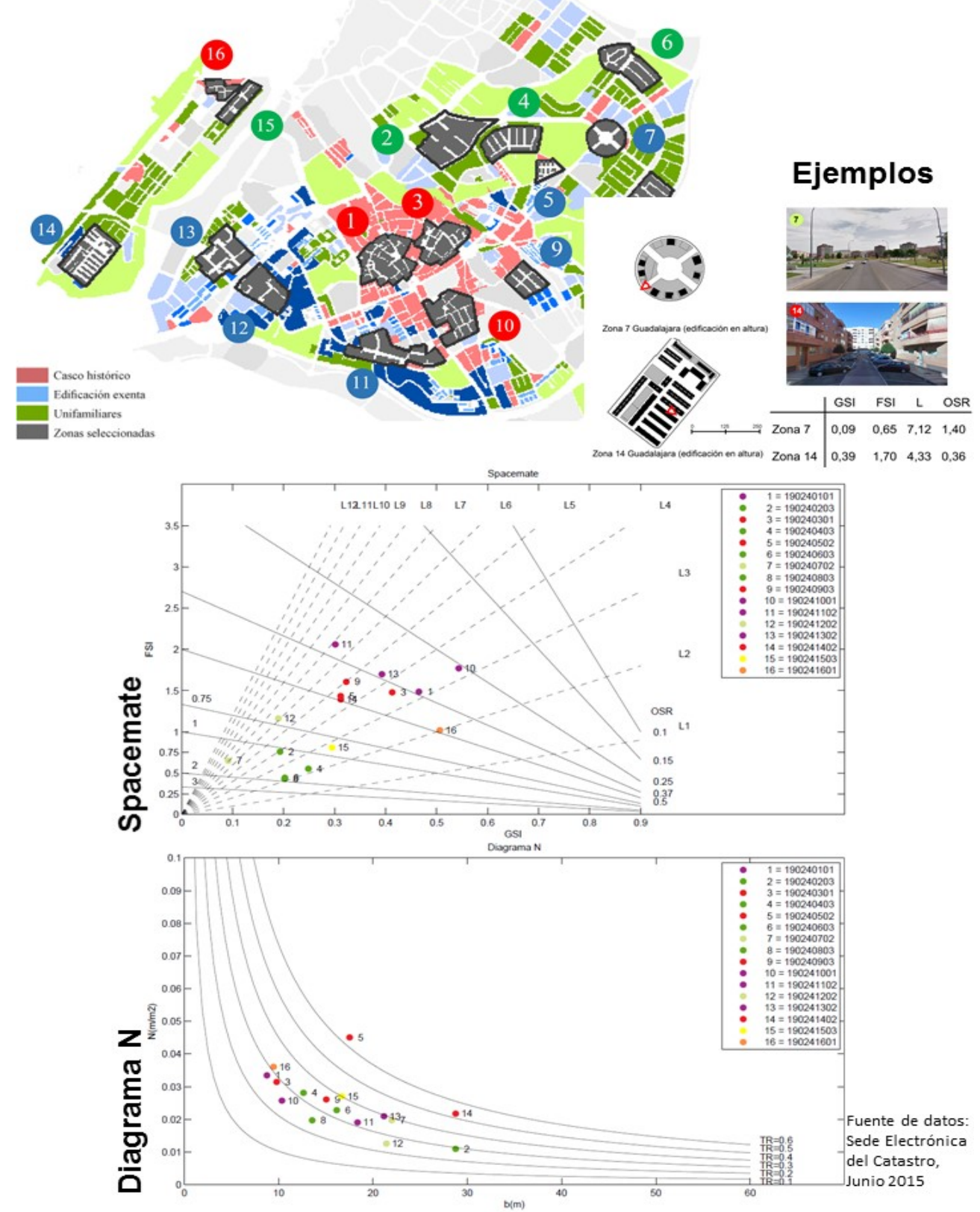

Fuente: Elaboración propia. 
Figura 6. Zonas seleccionadas del municipio de Toledo, Spacemate y Diagrama N.
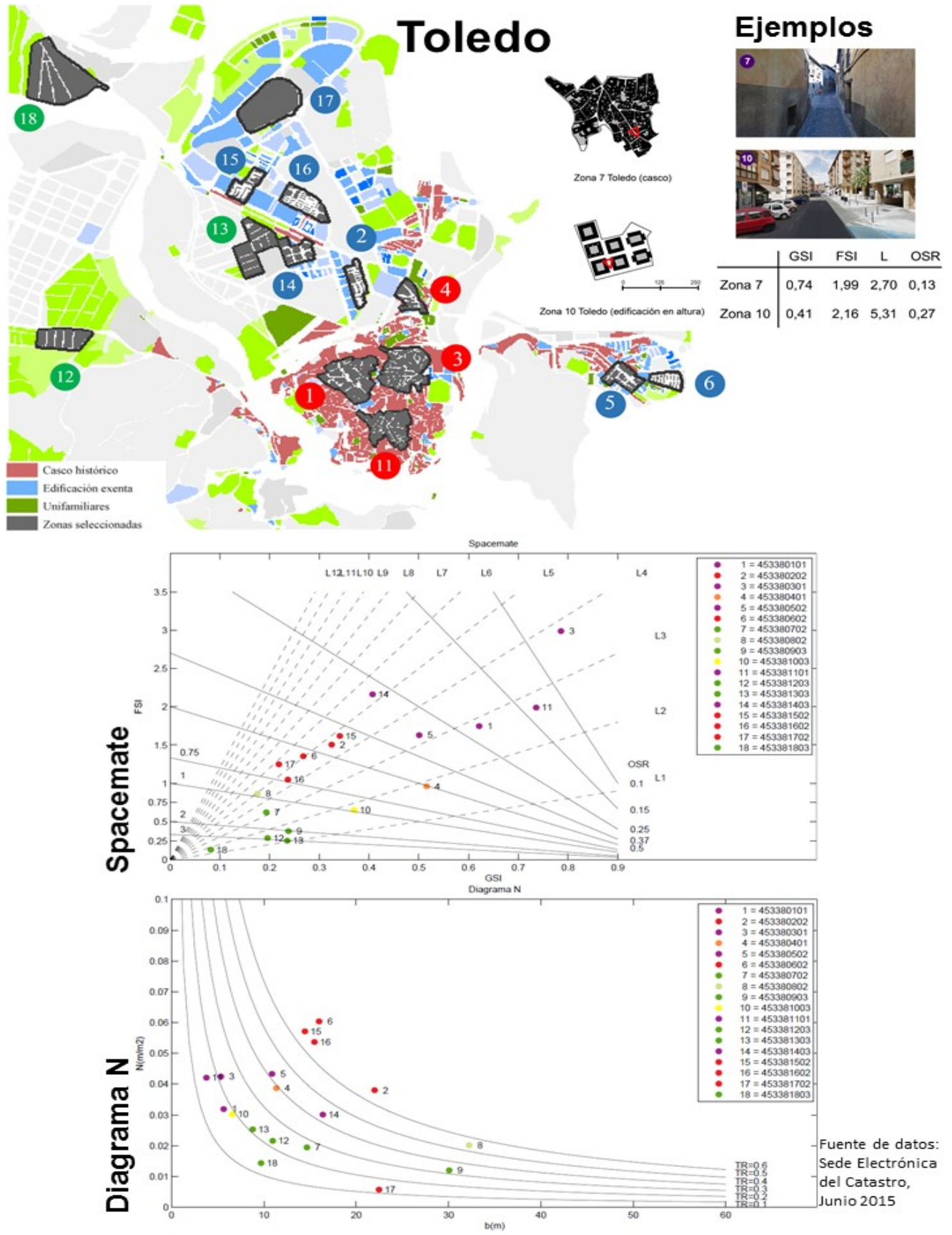

Fuente: Elaboración propia. 


\section{Discusión y conclusiones}

La identificación sistemática de formas urbanas permite un análisis de precisión de cada una de las partes y los tejidos que conforman la ciudad. El análisis comparado de la morfología de las cinco ciudades medias expuestas, desprovisto de coordenadas espacio-temporales, como el emplazamiento, la historia y evolución urbana, que lo contextualicen, se convierte en una potente herramienta cuantitativa con gran utilidad en el trabajo de diagnóstico y análisis de las formas urbanas para el desarrollo de planes de ordenación y políticas urbanas, y las estrategias de los agentes urbanos que intervienen en el territorio. No obstante, habría que completar este análisis con el estudio del marco legal y otros elementos de carácter geográfico y sociológico que no podemos olvidar (Solís et al., 2017). Además, el hecho de centrarse en ciudades medias, que suelen adolecer de estudios sistemáticos y comparativos, incrementa el interés de esta metodología.

Tras los resultados obtenidos puede comprobarse que las distintas formas urbanas se diferencian claramente a través de un método automatizado, objetivo y basado en parámetros y resultados numéricos, extrapolables y comparables. Esto permite realizar lecturas prácticamente instantáneas de las ciudades analizadas. Cada forma urbana obtenida y representada en la gráfica Spacemate tiene los mismos parámetros y ocupa exactamente las mismas posiciones para cualquier ciudad analizada, presentando únicamente ligeras variaciones de densidad y de alturas. Además, la información que aporta estos análisis es muy gráfica, por lo que las gráficas y planos pueden ser comprendidos por cualquier interesado en la ciudad, ya sean expertos urbanistas, ayuntamientos o empresas.

La fiabilidad de los resultados obtenidos es muy alta y la elección de las variables y los números de clústeres ha sido la correcta al observar los excelentes resultados. No obstante, el proceso presenta algunas limitaciones que tienen que ver con la confusión de edificios "modernos" arracimados (edificaciones exentas) con unifamiliares, ya que ambos poseen alturas y formas similares; y de polígonos industriales con unifamiliares, ya que los primeros presentan una regularidad parcelaria, unas ocupaciones, y un número de alturas muy similar a las promociones contemporáneas de unifamiliares, pero que se resuelve eliminando del proceso las construcciones con uso industrial.

Los resultados obtenidos muestran que las capitales provinciales de Castilla-La Mancha se caracterizan por tener densidades muy elevadas pero repartidas de manera irregular, concentrándose en los cascos históricos y en algunas promociones de edificaciones en altura. Esto hace que pueda haber problemas por falta de soleamiento en cascos históricos debido al elevado número de alturas de las edificaciones y a las calles estrechas. No obstante, los resultados muestran que el viario medio es aceptable para el conjunto de ciudades, aunque hay zonas de Ciudad Real, Cuenca o Toledo con anchos de calle de menos de 9 metros, mientras que los viarios más anchos se encuentran en las zonas que siguen las pautas del Estilo Internacional, donde se pueden superar los 40 metros de ancho. Esto genera una constante falta de aparcamiento y de soleamiento en los cascos históricos debido a que se combinan 
unas calles estrechas con una gran densidad, especialmente en ciudades como Ciudad Real, Cuenca o Toledo.

En último lugar, los resultados permiten clasificar las capitales provinciales de Castilla-La Mancha en dos grandes grupos. Por un lado, las capitales con casco histórico (Toledo, Cuenca, y Guadalajara) se caracterizan por disponer de un centro denso de origen medieval, o anterior, con unas alineaciones poco intervenidas, por lo que está poco modificado con respecto a su estado decimonónico. Esto hace que alrededor del mismo se hayan desarrollado promociones de vivienda en altura de gran densidad, tanto de tipo "moderno", como en forma de nuevo centro urbano. Las promociones de unifamiliares antiguas son poco numerosas, pues éstas se concentraban en el tejido medieval, pero sí hay gran cantidad de unifamiliares contemporáneos. En consecuencia, estas ciudades han crecido de manera horizontal por lo que son muy extensas para la población de que disponen. Por otro lado, las capitales sin casco histórico (Albacete y Ciudad Real) no respetaron su centro medieval, por lo que lo densificaron de manera constante sustituyendo los caseríos y los pequeños bloques de pisos por grandes edificaciones en altura de los años $60 \mathrm{~s}$ y 70s. Alrededor del casco se desarrollaron gran cantidad de promociones de unifamiliares antiguos y de elevada densidad, ciertos unifamiliares más modernos y menos densos, y algunas promociones de edificación extensa, éstas últimas no muy grandes. De esta forma, estas ciudades han crecido de forma vertical, concentrada en el casco, por lo que disponen de un centro muy denso, una periferia extensa y un tamaño no tan dilatado como en las anteriores.

\section{Referencias bibliográficas}

Appleyard, D. y Jacobs, A. (1984): Hacia un manifiesto por el diseño urbano, Ciudad y territorio: Revista de ciencia urbana 59-60, 69-78.

Bellet, C., Everaldo, S., Melazzo, M., Sposito, M. A. y Llop, J.M. (eds.). (2015): Urbanización, producción y consumo en ciudades medias/intermedias. Universitat de Lleida: Lleida.

Berghauser, M.Y. y Haupt P.A. (2005): The Spacemate: Density and the Typomorphology of the urban Fabric, Nordic Journal of Architectural Research 4, 55-68.

Berghauser, M.Y. y Haupt P.A. (2009): Space, Density and Urbam Form, Universidad Técnica de Delft: Delft.

Blasco, J. A. (2 de agosto de 2014): "Cuando el Plan de Bolonia era una referencia urbanística (y de izquierdas) para la intervención en los centros históricos de las ciudades (2. El Plan)", recuperado el 15/04/2016. Disponible en http://urbannetworks.blogspot.com.es/2014/08/cuando-el-plan-de-bolonia-era-una.html

Burriel, E.L. (2008): La "década prodigiosa" del urbanismo español (1997-2006). Diez años de cambios en el Mundo, en la Geografia y en las Ciencias Sociales, 1999-2008. Actas del $X$ Coloquio Internacional de Geocrítica, Universidad de Barcelona, 26-30 de mayo de 2008. <http://www.ub.es/geocrit/-xcol/383.htm> 
Capel, H. (1975): Capitalismo y morfología urbana en España, Los Libros de la Frontera: Barcelona.

Capel, H. (2006): La morfología de las ciudades (vol.1): sociedad, cultura y paisaje urbano. Serbal: Barcelona.

Capel, H. (2009): Las pequeñas ciudades en la urbanización generalizada y ante la crisis global. Investigaciones geográficas 70, 7-32.

Capel, H. (2016): La forma urbana en la ciudad postcapitalista. Biblio3W. Revista Bibliográfica de Geografía y Ciencias Sociales 21(1177).

Cebrián, A. y Panadero, M. (coords.) (2013): Ciudades medias: formas de expansión urbana. Biblioteca Nueva: Madrid.

García, F.M. (13 de junio de 2013): "Una metodología para la delimitación y clasificación de las formas urbanas en las ciudades intermedias españolas durante el siglo XX basada en SIG", en V Seminario Internacional de Investigación en Urbanismo, Barcelona-Buenos Aires, 1199-1215.

Conzen, M.P. (2001): The study of urban form in the United States, Urban Morphology 5(1), 3-14.

ESPON (2006): The Role of the Small and Medium-Sized Towns (SMESTO), Interim Report. Österreichisches Institut für Raumplanung.

European Environmental Agency - EEA (2006): "Urban Sprawl in Europe. The ignored challenge", EEA Report 10/2006.

Ganau, J. y Vilagrasa, J. (2003): Ciudades medias en España: Posición en la red urbana y procesos urbanos recientes, Mediterráneo Económico 3, 37-49.

Gauthiez, B. (2004): The history of urban morphology, Urban Morphology 8(2), 71-89.

Hernández-Aja, A. (1997): Análisis urbanístico de barrios desfavorecidos: catálogo de áreas vulnerables españolas, Ci[ur] 19.

Hillier, B. y Vaughan L. (2007): The City as One Thing, Progress in Planning 67(3), 205-230. Kostof, S. (1991): The City Shaped: Urban Patterns and Meanings through History. Bulfinch.

Larkham, P. (2006): The study of urban form in Great Britain, Urban Morphology 10(2), 11741

López de Lucio, R. (1996): Los nuevos ensanches de Madrid. Geometría: revista semestral de arquitectura y urbanismo 22, 41-47.

López de Lucio, R. (1997): Retículas y manzanas: configuración de sentido en las nuevas periferias: Una consideración equilibrada de los "ensanches" actuales. Urbanismo: revista oficial del Colegio de Arquitectos de Madrid 30, 6-17.

Mallarach, J. y Vilagrasa, I. (2002): Los procesos de desconcentración urbana en las ciudades medias españolas, Ería 57, 57-70.

Más, R. (1996): "Periferias urbanas y nuevas formas espaciales", en Domínguez, R. (coord.). La ciudad. Tamaño y crecimiento. Ponencias, comunicaciones y conclusiones del III Coloquio de Geografía Urbana, Antequera, 24-26 de junio de 1996. Málaga: Departamento de Geografía de Málaga/Asociación de Geógrafos Españoles, 1996, p. 210233.

Méndez, R. y Sánchez, S. (2011): Spanish cities in the knowledge economy: theoretical debates and empirical evidences, European Urban and Regional Studies 18(2), 136-155. 
Más, R. (1996): “Periferias urbanas y nuevas formas espaciales.” En Domínguez, R. (coord.): La ciudad: tamaño y crecimiento, III Coloquio de Geografía Urbana, Málaga: Universidad de Málaga, 201-233.

Moneo, R. (1982): “El urbanismo contemporáneo: 1950-1980”, en AAVV: Vivienda y urbanismo en España, Banco Hipotecario de España: Barcelona, 199-215.

Moudon, A.V. (1994): “Getting to know the built landscape: typomorphology", en Franck, K. y Scheekloth, L. (eds.): Ordering space; types in architecture and design. Van Nostrand Reinhold: New York.

Moudon, A.V. (1997): Urban Morphology as an emerging interdisciplinary field, Urban Morphology 1, 3-10.

Morris, A.E.J. (1979): History of Urban Form before the Industrial Revolution. Routledge: London.

Panerai, P., Castex, J., Depaule J.C. (1986): Formas urbanas: de la manzana al bloque, Gustavo Gili: Barcelona.

Panerai, P., Castex, J., Depaule J.C. y Samuels, I. (2004): Urban forms. The death and life of the urban blocks. Routledge: London.

Rodríguez-Tarduchy, M. J. (2011): Forma y Ciudad: en los límites de la arquitectura y el urbanismo, Citer Divulgación Técnica: Barcelona.

Romero, V., Garmendia, M. y de Ureña, J.M. (2014): The Spanish Cadastre: Office Location, Morphologies and Dynamics in Metropolitan Madrid, Boletín de la Asociación de Geógrafos Españoles 65, 271-291.

Ruiz-Apilánez, B., Solís, E. y Romero de Ávila, V. (coord.) (2017): Forma urbana: pasado, presente y perspectivas. Actas del I Congreso ISUF-H. Hispanic International Seminar on Urban Form, Cuenca, Ediciones de la Universidad de Castilla-La Mancha, 704 p. DOI: http://doi.org/10.18239/jor_12.2017.04.

Solà-Morales, M. (1997): Las formas de crecimiento urbano, Edicions de la Universitat Politécnica de Catalunya: Barcelona.

Solís, E., Romero, V., Moyano, A. y Coronado, J.M. (2017): Bases para reformular la política de vivienda en regiones rurales: caracterización del patrimonio residencial y condición socioeconómica de los municipios en Castilla-La Mancha, Cuadernos Geográficos 56(2), 176-199.

Troitiño, M. A. (1983): Centro histórico, intervención urbanística y análisis urbano, Anales de Geografia de la Universidad Complutense 11, 25-48.

Troitiño, M. A. (2001): Renovación urbana, dinámica y cambios funcionales, Perspectiva Urbana 2.

Vilagrasa, J. (1991): El estudio de la morfología urbana: una aproximación, Cuadernos críticos de geografía humana 92.

Vernez, A. (1997): Urban morphology as an emerging interdisciplinary field, Urban Morphology 1, 3-10.

Whitehand, J. W. R. (2001): British urban morphology: the Conzen tradition, Urban Morphology 5(2), 103-109.

Zárate, A. (1998): Forma urbana en Castilla-La Mancha, Espacio, Tiempo y Forma 11, 157187. 